\title{
COISA MAIS LINDA: A TRANSFORMAÇÃO DO DIREITO DE FAMÍLIA À LUZ DA TRANSFORMAÇÃO DOS DIREITOS DAS MULHERES.
}

\author{
BRUNA BARBIERI WAQUIM ${ }^{1}$ \\ HÉCTOR SANTANA VALVERDE ${ }^{2}$
}

\begin{abstract}
Resumo
O artigo trabalha a análise da série "Coisa mais linda", romance histórico ambientado no Rio de Janeiro da década de 1950. Cada uma das protagonistas traz uma história de vida que representa um dos pilares contemporâneos da modificação do Direito de Família: ingresso da mulher no mercado de trabalho; luta contra o preconceito racial e de gênero; rompimento do silêncio sobre violência doméstica e a autonomia civil feminina. As histórias se cruzam em laços de sororidade que permitem vislumbrar como a luta pelo reconhecimento da condição de sujeito de direitos das mulheres transformou o cenário jurídico brasileiro.
\end{abstract}

Palavras-chave: Capacidade civil; Direito e Arte; Direitos das mulheres; Direito de família; Violência de gênero.

\section{MOST BEAUTIFUL THING: THE TRANSFORMATION OF FAMILY LAW IN THE LIGHT OF THE TRANSFORMATION OF WOMEN'S RIGHTS.}

\begin{abstract}
The article analyzes the period drama "Most beautiful thing", a historical novel set in the Rio de Janeiro of the 1950s. Each of the protagonists brings a life story that represents one of the contemporary pillars of the modification of Family Law: entry in the business market; fight against racial and gender bias; breaking of silence on domestic violence and female civil autonomy. The stories intersect in sorority bonds that allow us to glimpse how the struggle for the recognition of the subject of women's rights has transformed the Brazilian legal scene.
\end{abstract}

\footnotetext{
1 Doutoranda em Direito pelo Centro Universitário de Brasília - UniCEUB/DF. Mestre em Direito e Instituições do Sistema da Justiça pela Universidade Federal do Maranhão - UFMA. Professora do Curso de Direito da Unidade de Ensino Superior Dom Bosco - UNDB. Assessora Jurídica no Tribunal de Justiça do Estado do Maranhão. End.: Rua Miquerinos, Ed. Executive Home, apt.1006, Renascença, São Luís/MA, CEP 65075-038. Email: bu_barbieri@yahoo.com.br

2 Doutor e Mestre em Direito das Relações Sociais - Direito do Consumidor - pela Pontifícia Universidade Católica de São Paulo. Professor do Centro Universitário de Brasília (UniCEUB) nos Cursos de Doutorado, Mestrado e Graduação em Direito, nas áreas de Teoria Geral do Direito, Direito do Consumidor e Responsabilidade Civil. Juiz de Direito Substituto de Segundo Grau do Tribunal de Justiça do Distrito Federal e Territórios. Membro Suplente do Tribunal Regional Eleitoral do Distrito Federal. End.: Doutorado em Direito. CEUB Campus Asa Norte, SEPN 707/907 - Bloco 3 - CEP 70790075 - Brasília-DF. E-mail: hectorvsantana@gmail.com
} 
Key-words: Civil capacity; Law and Art; Women's rights; Family law; Gender violence.

\section{INTRODUÇÃO}

Qual a exata repercussão da luta pelo reconhecimento da condição de sujeito de direitos das mulheres? Pode-se vislumbrar consequências na economia e no mercado de trabalho, na dinâmica da divisão de tarefas nos lares, no exercício da liberdade sexual, e de forma mais peculiar, na mudança de regras jurídicas consolidadas há muito no Código Civil e que representaram uma oxigenação do Direito de Família brasileiro.

É justamente essa inter-relação entre os direitos das mulheres e o Direito de Família que pode ser extraída do enredo da série "Coisa mais linda", produção brasileira da Netflix lançada no início do ano de 2019.

A série, ambientada no Rio de Janeiro da década de 1950, poderia facilmente se passar por mais um romance de época, não fossem as fortes personagens femininas que marcam presença na ficção com vivas cores de realismo.

Para discutir a contribuição da referida série à construção do pensamento científico no âmbito do Direito de Família, será utilizada como ferramenta metodológica a análise fílmica, por meio da qual será possível pontuar, a partir das vivências ficcionais das personagens, repercussões reais às transformações jurídicas da legislação e principiologia familista no Brasil.

Para tanto, será seguido o roteiro de Penafria (2009), que estabelece duas etapas importantes: em primeiro lugar, descrever e decompor para, em seguida, estabelecer e compreender as relações entre esses elementos decomposto, para compreender de que modo esses elementos foram associados num determinado filme.

Bertolin e Brito (2011) apontam que as artes em geral têm o papel primordial de expandir os conceitos de racionalidade da sociedade convencional, estimulando as pessoas a olhar o mundo de uma nova maneira. Especificamente em relação aos filmes, ao cinema, este tem a habilidade de modificar as suposições necessárias para 
a criação de uma nova imagem de pensamento filosófico, contribuindo para reavaliar a relação entre matéria e pensamento.

O presente artigo, portanto, se estrutura em três etapas: dissertar sobre as protagonistas da série "Coisa mais linda" e suas relações permeadas por diferentes graus e fontes de violência; identificar as transformações jurídicas que culminaram, no Brasil, com o reconhecimento das mulheres como sujeitos de direito; e, por fim, contextualizar as lutas das personagens ficcionais às reais conquistas alcançadas por meio da crescente autonomia das mulheres e seus reflexos no moderno Direito das Famílias.

A tempo de iniciar-se, então, este périplo.

\section{COMPREENDENDO O ENREDO DA SÉRIE “COISA MAIS LINDA”}

Toda exuberância do Rio de Janeiro, a "Cidade Maravilhosa”, no ano de 1959 ressoa das telas nas cenas iniciais da série. Um trecho do "Samba da Benção", de Vinicius de Moraes, é declamado pela voz da protagonista em meio a fogos de artifício e as ondas do mar de um provável réveillon em Copacabana: "Uma mulher tem que ter qualquer coisa além da beleza, qualquer coisa de triste, qualquer coisa que chora, qualquer coisa que sente saudade. Um molejo de amor machucado, uma beleza que vem da tristeza de se saber mulher". Quase como um prenúncio do que será assistido nos episódios.

A protagonista Maria Luiza sai do conforto da casa de seu rico pai em São Paulo para procurar seu esposo Pedro, que havia se mudado para o Rio de Janeiro para abrir um restaurante com o dinheiro de Maria Luzia (provavelmente oriundo de uma espécie de dote matrimonial).

Chegando em São Paulo, qual não foi a surpresa de Maria Luiza em encontrar apartamento do marido e futuro restaurante em completo estado de abandono; um estado de abandono externo que só não foi mais cruento do que o estado de abandono interno da personagem, ao descobrir que seu esposo mantinha relacionamentos extraconjugais enquanto ela acreditava estar ele construindo "o sonho" do casal. 
Após uma tentativa quase suicida de purificar pelo fogo a dor do luto pela partida do marido - Maria Luiza literalmente põe fogo nas fotos e roupas do agora exmarido - ela é socorrida pela "doméstica" Adélia, mulher negra forte e gentil que, com sua sororidade ${ }^{3}$, consegue transmitir um pouco de equilíbrio à sofrida Maria Luiza.

No Rio de Janeiro, capital política do país, Maria Luiza tem como ponto de apoio a amiga de infância Lígia, que prontamente lhe presta solidariedade ao acontecido e tem a grande ideia para resolver o problema: é só contar às pessoas que Pedro faleceu. Lígia mesma, porém, acaba contando tudo para Thereza, sua concunhada, que da mesma forma solidariza-se com Maria Luiza.

Para selar a despedida de Maria Luiza do Rio de Janeiro e seu retorno à segurança do lar do seu pai em São Paulo, as amigas vão para um passeio de barco: Lígia e seu esposo Augusto, um político machista em ascensão; Thereza e seu marido Nelsinho, irmão de Augusto e um playboy de bom coração - já que aceita muito bem o fato de sua esposa trabalhar como editora de uma revista feminina; e Maria Luiza, carregando toda a vergonha de uma jovem esposa abandonada e o fracasso do sonho de abrir um restaurante em que houvesse música.

É no barco também que dois importantes personagens são apresentados: Chico, cantor de uma misteriosa Bossa Nova, novidade musical, e Roberto, diretor de uma gravadora, os quais se tornarão as pontas de um discreto e platônico triângulo amoroso com a paulista.

Antes de ir embora do Rio de Janeiro, Maria Luíza aceita o convite de Chico para conhecer o Rio de verdade: os dois sobem o morro para que ela conheça o legítimo samba carioca e ouça um pouco mais da Bossa Nova. Ali, embebida pela música diferente, pela vista deslumbrante e pelos olhos de Chico, Maria Luíza vira "Malu", a paulista que decide que não precisa de um marido para realizar seu sonho de "viver de música": abrir um clube onde a música seja a principal oferta do cardápio.

Malu recebe vários nãos: do banco, do pai (que ameaça lhe cortar todo o auxílio financeiro caso não retorne a São Paulo e busque outro marido), do Roberto 
(a quem havia proposto sociedade), até do agiota com quem seu ex-marido tinha negócios. Voltando ao clube, em uma conversa sincera com Adélia, Malu declara: "Hoje ouvi de três homens diferentes que eu não posso fazer o que eu quero porque eu sou mulher".

A sociedade para abrir o clube "Coisa mais linda", porém, é concretizada: Malu se une a Adélia, por um contrato pro forma e sui generis. "Duas mulheres malucas realizando o impossível", é o que Malu escreve em um papel para que ambas assinem.

Durante as obras de reforma do restaurante, as histórias das coprotagonistas vão se desvelando: Lígia sofre em silêncio com os abusos físicos e sexuais do seu marido, que tolhe sua personalidade artística; Thereza sofre - embora com muita elegância e jogo de cintura, é fato - com a opressão masculina no ambiente de trabalho, além de carregar a dor pela perda de um filho; Adélia sofre pelo duplo castigo que a sociedade da época lhe impõe: não é apenas mulher, é uma mulher negra, tida como força de trabalho a ser explorada em estado de não-dignidade.

Para que não se chateie o leitor com spoilers, basta às finalidades do presente trabalho dizer que as histórias das personagens são desenroladas no seriado demonstrando toda a dificuldade com que o público feminino brasileiro lidou, à época, e na vida real, com os desafios para o reconhecimento da condição de sujeito de direitos das mulheres: 0 ingresso da mulher no mercado de trabalho; a luta contra 0 preconceito racial e de gênero, que inferiorizava mulheres e, pior ainda, mulheres negras; o difícil rompimento do silêncio sobre violência doméstica e a garantia da autonomia civil feminina sem a necessidade do casamento.

Estas questões são o pano de fundo não apenas de uma série de ficção brasileira que já se mostra tão bem sucedida, como também representa a oportunidade de debater a própria repercussão que a conquista dos direitos das mulheres causou na sociedade e no Direito de Família brasileiros, como se passa a discutir.

\section{DA INCAPACIDADE CIVIL À CHEFIA DA FAMÍLIA PELAS MULHERES NO BRASIL}


Tratar das transformações histórico-jurídicas dos direitos do público feminino perpassa, necessariamente, pela história constitucional do país, considerando o papel da Carta Constitucional na própria formação e manutenção dos valores (morais e jurídicos) elegidos pelo povo.

Nesse contexto, a primeira Constituição Brasileira, de 1824, não trazia a proibição expressa ao voto feminino, porém, não se deveria concluir, por isso, que era possível a concessão do direito ao voto às mulheres por lei ordinária (PORTO, 2000).

Daqui se extrai o primeiro registro jurídico da legalização da desigualdade de sexos: só os homens eram considerados cidadãos brasileiros, posto que somente eles poderiam votar.

O texto constitucional de 1824 menciona a mulher apenas ao dispor sobre a sucessão imperial, em seus artigos 116 e seguintes. Nesse momento constitucional, somente os cidadãos homens com 25 anos ou mais e todos que tivessem renda de 100 mil-réis poderiam votar; as mulheres e os escravos não eram considerados cidadãos, sendo os excluídos políticos no período imperial (SANTOS, 2009).

$\mathrm{Na}$ Constituinte de 1890, a discussão sobre o voto feminino foi intensa, e, embora o anteprojeto de Constituição não prescrevesse o sufrágio à mulher, na chamada Comissão dos 21, no Congresso, três deputados propuseram que ele fosse concedido às mulheres diplomadas com títulos científicos e de professora, desde que não estivessem sob o poder marital nem paterno, bem como às que estivessem na posse de seus bens. Adversários do voto feminino rebatiam a proposta com alegações que bem representavam o pensamento padrão da época: que, com essa concessão, se teria decretada a dissolução da família brasileira; que a mulher não possuía capacidade, pois não tinha, no Estado, o mesmo valor que o homem; e que a proposta do voto feminino era anárquica, desastrada e fatal (PORTO, 2000).

Apenas em 1879 o governo brasileiro havia possibilitado às mulheres cursarem o ensino de terceiro grau, mas as que buscavam este caminho estavam sujeitas ao preconceito social por seu comportamento contra a "natureza" (SANTOS, 2009 - grifos do autor), e a tradição "mansa e pacífica", no Brasil, de negativa do voto à mulher, somente seria quebrada com o Código Eleitoral de 1932 (PORTO, 2000 grifos do autor). 
A estruturação hierárquica da família patriarcal brasileira legitimava a condição social que se avaliava pela estirpe. Para atender às funções de transmissão do status e do patrimônio, servindo, por conseguinte, à manutenção do poder político, a estabilidade do corpo familiar era essencial: o patriarca centralizava a direção da família; a esposa tinha como papel definido nessa estrutura familiar a subordinação, papel para o qual era criada desde a mais tenra infância; as filhas eram criadas para ocuparem seu papel de boas esposas para a família de seus futuros maridos, e o desenvolvimento das virtudes das "boas moças" 4 era fator indispensável à obtenção de casamentos - e alianças - vantajosos com outros fazendeiros e homens de posse, "bem nascidos", de modo a assegurar a manutenção do status e da condição econômica (RUKYZ, 2005 - grifos do autor).

A legislação brasileira até 1916 era, nas palavras de Silvio Rodrigues (1993), um "cipoal"5: várias normas disciplinavam o Direito Civil brasileiro, como as Ordenações Portuguesas e Filipinas, Alvarás, Leis, Decretos, Resoluções, Usos e Costumes, a consolidação de Teixeira de Freitas, a compilação de Carlos de Carvalho, até que foi promulgado o Código Civil brasileiro de 1916.

O Código Civil de 1916 foi promulgado garantindo proteção legal à tradicional família de então, caracterizada por ser matrimonializada, patriarcal, hierarquizada, heteroparental, biológica e institucional, vista como unidade de produção e de reprodução (MADALENO, 2011).

Dias $(s / d, b)$ revela:

O Código Civil de 1916 era, na verdade, uma codificação do século XIX, pois foi no ano de 1899 que Clóvis Beviláqua recebeu o encarrego de elaborá-lo. Retratava a sociedade da época, marcadamente conservadora e patriarcal. Assim, só podia consagrar a superioridade masculina. Transformou a força física do homem em poder pessoal, em autoridade, outorgando-lhe o comando exclusivo da família. Por isso, a mulher ao casar perdia sua plena capacidade, tornando-se relativamente capaz, como os índios, os pródigos e os menores. Para trabalhar precisava da autorização do marido.

4 Laurentino Gomes (2013) ressalta que a submissão da mulher era um traço tão característico que influenciou até mesmo a arquitetura das casas nos primeiros séculos da história do Brasil, que possuíam janelas por trás, por meio das quais as mulheres, que nunca saíam de casa, podiam observar a rua sem serem vistas.

5 “Cipoal. ci·po·al. Sm. 1 Mata abundante de cipós, tão enredados que dificultam o acesso e o trânsito; cipoada. 2 fig Situação difícil; cipoada, embaraço, embrulhada. 3 fig Negócio intricado, de difícil solução; cipoada, enrascada.” (CIPOAL, 2019) 
A redação original do artigo 380 do Código Civil de 1916 atribuía o "pátrio poder" 6 ao marido, eis que era o chefe da família, e apenas na sua falta ou impedimento que essa autoridade era concedida à mulher. Somente com o advento do Estatuto da Mulher Casada (Lei no 4.121/1962) é que o referido artigo foi alterado para, reconhecendo em parte a igualdade jurídica da mulher, dizer que pátrio poder competia ao pai e deveria ser exercido "com a colaboração da esposa" (AZEVEDO, 2013, p.279).

Avançando no tempo, o estabelecimento do Estado Novo em 1937 mudou por completo a política eleitoral, pondo fim ao embrião do movimento feminista presente no Brasil nos anos 1920 e 1930. O novo regime, seus líderes e sua ideologia demonstraram hostilidade quanto às demandas femininas, em especial quanto às pretensões de assegurar a igualdade entre os sexos (SCHNEIDER, 2014).

Se nas décadas de 1960 e 1970 o feminismo foi impulsionado na Europa e nos Estados Unidos, muito em parte pela efervescência política e cultural que essa regiões passavam na época, que ameaçavam os valores conservadores da organização da sociedade, no Brasil, o cenário era bem diferente. O país estava vivendo uma ditadura militar no auge da repressão, mas, ainda assim, as brasileiras organizaram-se, independentemente de partidos políticos, idade e classe social, para formar uma militância contra o regime militar. Muitas eram esposas que viram os maridos serem torturados e assassinados pelo governo militar. Esse movimento independente, alheio a partidos políticos e outras ideologias, foi muito apreciado pela sociedade, dando espaço à simpatia de vários grupos políticos (SANTOS, 2009).

Finalmente, foi promulgada a Constituição da República de 1988, ressignificando todo o sistema jurídico a partir do primado da Dignidade da Pessoa Humana e, ao que mais importa para o presente trabalho, da Repersonalização do Direito Privado.

A atenção despertada pelo legislador constituinte de 1988 em elevar o Direito de Família ao âmbito constitucional, cujas regras jurídicas até então eram buscadas na legislação ordinária, abriu espaço para que toda a principiologia da Constituição de 
1988 se prestasse ao serviço da nova configuração das famílias, particularmente os princípios fundamentais da dignidade da pessoa humana e da cidadania, além dos objetivos fundamentais de construir uma sociedade livre e solidária, garantindo o bem de todos, sem preconceitos ou qualquer forma de discriminação, conforme expressa dicção dos artigos 1ํ e $3^{\circ}$ da Constituição Federal (WAQUIM; SOUSA, 2015).

A antiga ideia de "família-instituição" (de proteção justificada por si mesma, admitindo mesmo violações dos interesses das pessoas nela compreendidas), foi então substituída pela noção de "família-instrumento do desenvolvimento da pessoa humana", passando a vedar qualquer interferência ou violência que viole os interesses dos seus membros. A família passa a existir em razão de seus componentes, e não estes em função daquela (FARIAS; ROSENVALD, 2010).

Abriu-se, assim, caminho para consolidação dos direitos humanos femininos, conferindo às mulheres igualdade, cidadania, proteção legal, vez e voz nos espaços públicos e privados.

Rompendo com todas as disposições discriminatórias de gênero, o novo Código Civil atendeu aos anseios feministas e eliminou qualquer tipo de submissão legal da mulher ao seu marido. A mulher casada, finalmente, não estava mais sob o jugo do marido e caso decidisse se separar não perderia o direito sobre seus filhos ou sobre sua propriedade, caso fosse configurado o abandono de lar (MAGALHÃES, 2016).

A década de 2000 deu continuidade a esse processo de luta. Ampliou-se o avanço legislativo, e por meio do trabalho de advocacy ${ }^{7}$ das organizações feministas e movimentos de mulheres, especialmente a partir da $1^{\text {a }}$ Conferência Nacional de Políticas para as Mulheres, um conjunto de demandas foi incluído em documentos e planos governamentais. Esses documentos se constituíram em parâmetro para orientar políticas públicas com a transversalidade de gênero e de raça/etnia. Também nessa década, os programas governamentais de redução da pobreza tiverem impactos positivos sobre a vida de grande parcela da população feminina (PITANGUY; BARSTED, 2011).

7 “Uma ação de advocacy para a configuração de direitos no plano normativo e/ou de políticas públicas e espaços institucionais para sua efetivação tem, nos seus bastidores, um processo de articulação de demandas e definição de estratégias de encaminhamento. $\mathrm{O}$ alcance dos objetivos propostos depende largamente da capacidade dos grupos envolvidos se manterem coesos e visíveis em meio a interesses conflitantes" (PITANGUY, 2011). 
Leis como a Lei Maria da Penha ( $n \cong 11.340 / 2006$ ), Lei de Alimentos Gravídicos ( $n^{\circ}$ 11.804/2008) e Lei do Feminicídio (no 13.104/2015) representam a concretização de importantes conquistas para proteção e dignidade das mulheres.

Magalhães (2016) elucida, com grande perspicácia:

As alterações legislativas quanto a um tema polêmico geralmente ocorrem
após a consolidação dessa nova opinião na sociedade. A equidade de gênero
sempre foi, e continua sendo, matéria de debates acalorados e infindáveis,
afinal, a sociedade brasileira ainda tem resquícios de uma cultura machista e
patriarcal. Dessa forma, a igualdade de direitos entre homens e mulheres no
matrimônio, do direito à pensão e ao poder familiar sobre os filhos -
denominação que substituiu o nome "pátrio poder" no Novo Código Civil para
consolidar a ideia de que tal poder deve ser exercido, conjuntamente, pelos
pais - apenas foram incorporados ao nosso ordenamento jurídico quando a
própria sociedade já clamava por esses direitos.

Não sem razão, Maria Berenice Dias estatui que "A trajetória da família está muito ligada à emancipação feminina". Ainda que lenta, a conquista de um espaço de cidadania pelas mulheres abalou a organização da família, forçando o declínio da sociedade patriarcal (DIAS, sd, a).

O número de famílias chefiadas por mulheres praticamente dobrou no país: cerca de 30 milhões de lares brasileiros são comandados por mulheres. Esses dados indicam melhora nas relações de gênero, embora ainda existam desafios importantes a serem vencidos, como uma divisão mais justa dos afazeres domésticos, um importante fator para garantir igualdade de oportunidades no mercado de trabalho, por exemplo (EM 15 ANOS..., 2018).

É diante desse cenário que surge a presente proposta de artigo. Assistir ao seriado "Coisa mais linda" é mergulhar na história de anteontem, em que mulheres lutavam por direitos hoje tão simples como o de ter a própria integridade física e moral respeitada, como será contextualizado a seguir.

\section{COISA MAIS LINDA É A CORAGEM DE TRANSFORMAR O DIREITO DE FAMÍLIA PELOS DIREITOS DAS MULHERES}

"O critério de sexo tem sido fundamental para demarcar a menos valia das mulheres traçando, ao longo dos séculos, um caminho de menor titularidade" (PITANGUY, 2011). 
Essa afirmação, embora dolorosa, tem fundamentos históricos: na Grécia Antiga, as mulheres e os escravos estavam excluídos dos direitos de cidadania. Enquanto era teoricamente possível ao escravo alcançar a liberdade em virtude de feitos heroicos, para as mulheres não havia possibilidade de superar sua condição de sexo. Durante o Império Romano, também eram as mulheres excluídas da esfera política e subordinadas ao homem no âmbito da vida privada, com base no do conceito de pater familiae. Na Alta Idade Média, ocorreu um retrocesso significativo no que se refere aos direitos humanos e, em particular, aos direitos das mulheres. O poder feudal descentralizado era exercido de forma absoluta e legitimado enquanto poder aprovado por Deus. Finalmente, o advento da chamada Era das Revoluções representa um locus fundamental na trajetória dos direitos humanos: traz a marca das desigualdades então vigentes e das lutas das mulheres por direitos iguais (PITANGUY, 2011).

Mesmo com o peso dos séculos de invisibilidade e opressão legitimados pelo sistema jurídico e pelo Poder estatal, lutar por um lugar de fala e representatividade fez da categoria vulnerável "mulheres" ampla fonte de transformações sociais.

A conquista das personagens Adélia e Malu de abrirem, sozinhas, o clube "Coisa mais linda", no seriado homônimo, é um retrato das vicissitudes da época: descrédito social e descrédito familiar. Uma passagem do seriado é especialmente marcante para demonstrar o fosso existente entre os sexos: o cantor Chico é convidado para a noite de estreia, porém chega bêbado, mal canta uma música e ainda arruma uma briga antes de sair. Para não estragar a festa, Malu sobe ao palco para entreter os convivas, convence Lígia a cantar e a noite termina, aparentemente, como um sucesso.

No dia seguinte, é publicada a crítica sobre o evento em um prestigioso jornal. Quem é elogiado? Chico, cujo (mau) comportamento parece ser justificado pelo simples fato de ser homem. Quanto a Malu e a Lígia, são ridicularizadas, mesmo tendo sido as únicas responsáveis por salvar a noite.

Mas não é só o ingresso da mulher no mercado de trabalho que rompe barreiras do preconceito e garante espaços de dignificação da mulher.

Grande parte dos avanços tecnológicos e sociais estão diretamente vinculados às funções da mulher na família: descoberta de contraceptivos eficazes, com planejamento familiar efetivo; fertilização manipulada; liberação do aborto; 
dessacralização da maternidade como imprescindível; dessacralização do casamento, com novas formas de conjugalidade; dissociação entre sexo e afeto; implantação da educação equalitária, com respeito às diferenças; crescimento e divulgação dos movimentos feministas, com leis avançadas, imbuídas de proteção à mulher e que minaram a hierarquização entre os gêneros (SOUZA; DIAS, sd).

Tais transformações repercutiram no Direito de Família: a regulamentação das técnicas de reprodução assistida, a garantia do direito ao planejamento familiar, a previsão da guarda compartilhada, a superação da culpa na dissolução conjugal, a guarida à família monoparental, a igualdade dos genitores no exercício da autoridade parental e dos cônjuges no exercício dos direitos e deveres conjugais, entre outros.

A personagem Thereza carrega uma rica fusão de modernidades: é uma mulher branca de classe média alta que trabalha, sendo a única mulher presente na editora de uma revista feminina (todos os demais jornalistas e cronistas são homens usando nomes de mulheres na publicação); exerce sua sexualidade sem amarras, ao lado e com o marido (somente assistindo ao seriado para compreender); não se sente frustrada pela ausência de filhos nem é vitimizada no casamento por, aparentemente, demonstrar uma incapacidade para gerar. Thereza é uma personagem contemplada pelos novos ares da família contemporânea, que realmente garante aos seus membros um espaço de realização pessoal.

Importa relembrar que o Direito de Família é o mais humano dos direitos, pois lida com as mais íntimas relações humanas, nas quais flagra de modo ímpar as grandezas e as pequenezas do ser humano. Originado e assegurado pelo afeto, o lar é o recinto basilar da família. Para ela a família converge. Nele a família convive. Por isso, nos seus vários aspectos, o físico, o social, o econômico e o psíquico, o direito ao lar se associa aos demais direitos operacionais ${ }^{8}$ da família: não só aos direitos que garantem a infra-estrutura física da família (como o direito à moradia e ao bem de família), como os direitos que promovem e protegem a família em sua estrutura social, como o próprio direito de igualdade entre o marido e a mulher, o direito ao poder familiar (BARROS, 2004, pp.607-613).

8 "Direitos operacionais ou instrumentais", para Barros (2004), seriam os direitos mais concretos e particulares, que são instrumentos de realização daqueles mais abstratos e gerais. 
E é no espaço da família - e da regulamentação da família - que o reconhecimento jurídico da capacidade civil, da autonomia privada e da dignidade da mulher causam as maiores transformações.

Por exemplo: ao assumirem a condição de "sujeitas de desejo", o princípio da indissolubilidade do casamento ruiu, pois era a resignação histórica das mulheres que sustentava os casamentos (DIAS, sd, a).

A personagem Lígia sofre, calada, várias agressões psicológicas, verbais, físicas e até mesmo sexuais do marido. É muito impactante assistir ao processo de enraizamento da culpa, como se o comportamento feminino pudesse justificar esse tipo de correção por parte do agente masculino - em várias ocasiões ela verbaliza e internaliza: "a culpa foi minha". O pensamento da personagem, que bem espelha o pensamento médio da época, era de que a santidade do casamento deveria ser resguardada a qualquer custo - inclusive a custos pessoais.

Mas ao ser convidada a subir no palco do clube "Coisa mais linda" para cantar, Lígia parece se empoderar também da sua voz interior e, quando renovada a violência física e psicológica motivada pelo ciúme que sua voz e sua beleza física causam a seu esposo, finalmente Lígia tem a coragem de reconhecer em tom solene, em uma conversa pós-agressão com Malu: "acho que meu casamento acabou".

Essa resistência a reconhecer certos casamentos como espaço de opressão leva Alves (sd) a afirmar:

Uma avaliação do fenômeno social do casamento enquanto contrato, dentro de uma abordagem feminista crítica, deve considerar, necessariamente, as ponderações formuladas por Carole Pateman (1993) acerca da teoria do contrato sexual. A partir destas lentes, torna-se possível constatar que o contrato de casamento, enquanto principal acordo que cria a família nos moldes patriarcais, tem sido, desde o início da teorização contratual, concebido possuindo como pressuposto a subordinação das mulheres ao domínio masculino, como se isto resultasse de uma ordem naturalmente preestabelecida. Dentro deste contexto, a ideia de família patriarcal desenvolve-se comum caráter a-histórico e a-político, tornando-se invisível às análises políticas liberais e, portanto, não se submetendo a qualquer avaliação sob parâmetros de justiça. (...)Segundo Pateman, a história do contrato social versa sobre uma ideia de conquista da liberdade civil onde os homens abrem mão das inseguranças do estado natural por uma liberdade garantida pelo Estado. No entanto, esta liberdade pertenceria unicamente aos indivíduos, homens adultos, dotados de capacidade para firmar contratos. $\mathrm{O}$ contrato sexual, por sua vez, vem trazer à tona um aspecto omisso nessa teorização, que é completamente inverso à ideia de liberdade: a sujeição. Pateman afirma que, enquanto "o contrato social é uma história de liberdade; o contrato sexual é uma história de sujeição" (1993, p. 16). Assim, a ideia global de contrato original cria, ao mesmo tempo, contraditoriamente, a liberdade do homem e a sujeição da mulher. Desta forma, a liberdade civil 
não é uma característica, como se preceitua teoricamente, universal, mas sim um atributo masculino.

A história da mulher no Direito, em geral, é de um "não-lugar", uma história de ausência, já que ela sempre esteve subordinada ao pai ou ao marido, sem autonomia e marcada pelo regime da incapacidade ou capacidade jurídica. A reinvindicação da igualização de direitos é a reinvindicação de um lugar de sujeito, inclusive de um lugar social. Foi esse assujeitamento histórico da mulher aos homens que levou Lacan a construir um aforismo que até hoje provoca muito incômodo e inquietação: "a mulher não existe". Foi a partir desse aforismo e da Psicanálise que se começou a pensar no desconhecido mundo feminino, já que todas as referências de identidades sociais foram feitas a partir do patriarcalismo (PEREIRA, 2006, pp.142-143).

Nos postulados freudianos, a inferioridade da mulher ganha contornos científicos ao reafirmar a incompletude e o complexo de castração diante do universo masculino. De um lado a Igreja, de outro o Estado patriarcal, e a ciência epistemologicamente masculina a legitimar a condição subalterna feminina, dentro de uma ideologia determinista biológica (SCHNEIDER, 2014).

$E$ isto é muito presente na personagem Adélia, uma mulher forte, trabalhadora, mas que por reunir os caracteres de mulher e negra, vive e convive em um estado de invisibilidade e eterna submissão ao outro: a patroa a trata como um animal de carga; o namorado Capitão entra e sai de sua vida sem que isso represente abandono; a própria irmã de Adélia dela se aproveita financeiramente, vivendo noites de farra às custas do trabalho da irmã, e até mesmo o primeiro (e desconfortável) encontro entre Lígia e Adélia é marcado pela forma com que socialmente a moça negra é tratada: se está presente no local, presume-se que é porque deve ser a empregada.

As coprotagonistas de "Coisa mais linda" permitem refletir como era custoso nascer mulher na sociedade brasileira da década de 1950. Não só por uma questão dos costumes moralistas e sexistas da época, mas pela própria legitimação desses costumes pela norma jurídica de então - ainda não existia o Estatuto da Mulher Casada, que permitiria à mulher assenhorar-se da própria capacidade de praticar atos da vida civil. Por isso, o seriado "Coisa mais linda" serve à licença poética de se problematizar o sexismo jurídico. 
O antisexismo, no campo do direito, tentaria eliminar todos os conceitos que tenham como base as características naturais do sexo, levando em conta não só a norma jurídica em si, mas também, e principalmente, as interpretações, os critérios de aplicação e as apreciações sociais e culturais predominantes (ALVES, sd).

E esta realidade não foi vivenciada apenas no Brasil.

A ideologia e as práticas herdadas do século XIX impuseram por toda a Europa o modelo social e jurídico da família nuclear (pai, mãe e filhos), assente numa cultura da família e do casamento, modelo este submetido a um conjunto de normas rígidas acerca das funções da família e dos papéis desempenhados por cada cônjuge. Vigorava um estatuto desigual para os homens e as mulheres, pois o homem tinha o direito, e também o dever, de procurar realizar o seu percurso individual fora de casa, enquanto o papel reservado à mulher era o de lhe proporcionar o conforto doméstico e afetivo de que precisava. Ao final do século XX, os ideais de democratização da família lograram libertar a mulher desse estatuto desigual, conferindo-lhe um estatuto de igualdade perante a sociedade e a lei: dois parceiros conjugais sujeitos ao mesmo processo de renascimento da subjetividade, procurando cada membro do casal a maior realização pessoal e satisfação que puder, dentro da comunhão de vida. Ou seja, dentro da igualdade, cada um busca a sua diferença, de acordo com a manifestação de suas próprias pretensões (PEDROSO, BRANCO, 2008).

Porque as mulheres têm sido privadas, ao longo dos séculos, do exercício pleno de direitos humanos e submetidas a abusos e violências, tanto em situações de guerra como no espaço da vida familiar e doméstica, seu papel tem sido de grande relevância na ampliação do alcance dos direitos humanos. Questões que sempre fizeram parte da sua agenda, como a violência doméstica, os direitos sexuais e reprodutivos, direitos sociais específicos da mulher, como o de herdar e ser proprietária, muito restringido em países islâmicos, a violação de sua integridade física, entre outros, vêm sendo colocadas por estes movimentos nas pautas de discussões das Nações Unidas (PITANGUY, 2011).

Citando os trabalhos de Amartya Sen, Waquim e Sousa (2015) analisam como as mulheres passaram historicamente a se apoderar da condição de agentes, ou seja, passaram a ser vistas pelos homens e por elas próprias como agentes ativos de mudança, promotoras dinâmicas das transformações sociais: estudos indicam que a 
alfabetização feminina influencia de forma determinante a redução da mortalidade das crianças de até cinco anos de idade; o acesso à educação, embora possa provocar a redução das taxas de fecundidade (porque os efeitos adversos de uma elevada taxa de natalidade incluem a negação de liberdades substanciais, devido a gestações frequentes e do trabalho incessante de criar os filhos), é importante pois a educação das mulheres contribui para ampliar seus horizontes e difundir os conhecimentos sobre planejamento familiar, inclusive com a reflexão de como a vida dos outros pode ser fortemente afetada por suas próprias ações.

As mulheres brasileiras realizaram um formidável trabalho de advocacy durante as Conferências das Nações Unidas, realizadas na década de 1990 e início dos anos 2000, conquistando importantes avanços nas esferas internacional/regional, afirmando de forma transnacional uma plataforma de direitos humanos das mulheres. Nesta, a violência doméstica passou a ser reconhecida como uma violação de direitos humanos (Conferência Internacional de Direitos Humanos, Viena, 1993); as questões ligadas à reprodução deslocaram-se da matriz demográfica para a matriz dos direitos reprodutivos (Conferência Internacional de População e Desenvolvimento, Cairo, 1994); os direitos sexuais bem como uma ampla plataforma de direitos das mulheres foram reafirmados, na IV Conferência Mundial das Mulheres, Beijing, 1995, e a questão do racismo foi aprofundada na Conferência Internacional Contra o Racismo, a Discriminação Racial, a Xenofobia e Intolerâncias Correlatas, Durban, 2001 (PITANGUY, 2011).

Assistir a coragem das protagonistas de "Coisa mais linda" é ter um vislumbre da ousadia, esperança e firmeza de espírito das mulheres de mil rostos que devotaram suas vidas privadas, suas imagens e suas reputações à defesa do direito de ser mulher: não inferior, nem frágil, nem posse, mas apenas ser humana, com todos os caracteres sociojurídicos dessa condição decorrentes.

É certo que a Constituição Federal e a legislação ordinária podem fazer distinções e dar tratamento diferenciado de acordo com juízos e critérios valorativos, razoáveis e justificáveis, que visem conferir tratamento isonômico aos desiguais. Porém, só valem as discriminações contidas na Constituição Federal que visem assegurar a igualdade de direitos e obrigações, entre homens e mulheres, como, por exemplo: 0 artigo $7^{\circ} \mathrm{XVIII}$ que dispõe sobre a licença à gestante em período superior 
à licença-paternidade e, ainda, o artigo 40, parágrafo 1, III, a e b, bem como o artigo 201, parágrafo $7^{\circ}$, da Constituição Federal, que dão tratamento diferenciando à mulher, diminuindo o tempo necessário para se aposentar (BARRETO, 2010).

$\mathrm{O}$ tratamento igualitário entre homens e mulheres, previsto no inciso $\mathrm{I}$, do artigo 5,ํำ da Constituição Federal, portanto, pressupõe que o sexo não possa ser utilizado como discriminação com o propósito de desnivelar substancialmente homens e mulheres, mas pode e deve ser utilizado com a finalidade de atenuar os desníveis social, político, econômico, cultural e jurídico existentes entre eles (BARRETO, 2010).

De fato e de direito, as transformações jurídicas não são suficientes para assegurar a igualdade social, política e econômica entre homens e mulheres. Hoje, a maioria dos direitos são garantidos por diversos instrumentos legais, porém, as mulheres brasileiras continuam sendo discriminadas, violentadas - psicologicamente e fisicamente - menosprezadas e inferiorizadas. Neste contexto, a responsabilidade pela efetiva igualdade é nossa, mediante a destruição definitiva da cultura machista e renovação da estrutura social, conferindo à mulher a sua devida posição: exatamente igual à que homem ocupa (MAGALHÃES, 2016).

Atualmente, são comuns mulheres presidentes de associações de bairro, dirigentes de ONGs, integrantes de movimentos sociais. Porém, a intensa participação política das mulheres tem como ponto de observação os espaços informais de poder. Isso significa que, embora muitas mulheres exerçam a direção de associações de bairro e de organizações civis em geral, essa participação não é refletida, na mesma proporção, quando analisamos os poderes institucionais do Estado Brasileiro. As chefias de órgãos e entes públicos ainda são, na maioria, ocupadas por homens, inclusive no Congresso Nacional. Esse fato ajuda a desmistificar o regime de cotas, porque não garante a inserção social, quer seja instituído no poder legislativo, ou nas universidades, ou em qualquer outro seguimento no Brasil (SANTOS, 2009).

É necessário, assim, a conscientização sobre as diferentes formas de violência contra a mulher: a violência simbólica (uma relação de submissão que sequer é reconhecida pelo dominado), a violência estrutural (derivada de condições de desigualdade social), tão perigosas quanto as já conhecidas violências física, sexual e psicológica. 
A violência simbólica se institui por intermédio da adesão que o dominado não pode deixar de conceder ao dominante (e, portanto, à dominação) quando ele não dispõe, para pensá-la e para se pensar, ou melhor, para pensar sua relação com ele, mais que de instrumentos de conhecimento que ambos têm em comum e que, não sendo mais que a forma incorporada da relação de dominação, fazem esta relação ser vista como natural; ou, em outros termos, quando os esquemas que ele põe em ação para se ver e se avaliar, ou para ver e avaliar os dominantes (elevado/ baixo, masculino/ feminino, branco/ negro etc.), resultam da incorporação de classificações, assim, naturalizadas, de que seu ser social é produto (BOURDIEU, 1999, p.47).

A violência estrutural representa a violência gerada por estruturas organizadas e institucionalizadas, naturalizada e ocultas em estruturas sociais, expressando-se na injustiça e na exploração. É uma violência infligida por instituições clássicas da sociedade e expressa em esquemas de dominação de classe, de grupos e do Estado, consagradas por sua tradição e poder e, na maioria das vezes, não contestada. Os sujeitos sociais sofrem os efeitos dessa violência estrutural a partir dos mecanismos pelos quais o Estado, em seus diferentes níveis e poderes, restringe o acesso da grande maioria da população aos direitos básicos que lhes proporcionariam uma vida digna, gerando assim um grave quadro de exclusão social (DIAS ALMEIDA; COELHO, 2007).

As transformações legais já consolidadas no espaço do Direito de Família são importantes, mas ainda não representam o último estágio de aperfeiçoamento dos institutos e das instituições em prol da igualdade formal e material das mulheres. Ainda assim, representam importantes indicativos dos novos tempos de respeito à autonomia e dignidade do público feminino, caracteres que ainda demandam contínua defesa e ressignificação nas relações sociais, familiares, jurídicas e políticas.

Afinal, "não só de mudanças legais se faz justiça" (MAGALHÃES, 2016).

\section{CONSIDERAÇÕES FINAIS}

A série brasileira "Coisa mais linda", da Netflix, é um pretexto - bem ensaiado, bem produzido e bem agradável de se assistir - para refletir sobre o que já falava Simone de Beauvoir na década de 1940: "Não se nasce mulher, torna-se mulher". 
As histórias de vida das protagonistas do filme mostram que estas podem até ter nascido mulheres, mas se recusaram a ceder aos estigmas da época sobre o que significava "ser mulher": resumir-se à aparência física; assombrear-se da presença de um homem (pai ou marido); resignar-se à violência doméstica em prol da indissolubilidade do vínculo do casamento; assentir com assédios morais e sexuais; aceitar um papel de coadjuvante de sua própria vida.

Dos enredos de cada personagem, é possível enxergar o pano de fundo de intensos embates e sacrifícios em prol da hoje - ainda não tão - conquistada autonomia, capacidade civil e liberdade das mulheres, objeto de séculos de luta.

Essas conquistas representaram grandes transformações na regulação normativa da família: cessou a subjugação da mulher à chefia da sociedade conjugal ao marido; compartilhou-se a autoridade parental entre ambos os genitores; permitiuse a liberdade no planejamento familiar, com a adoção de métodos contraceptivos ou métodos de reprodução humana assistida; a constituição de uma família independente da existência de uma relação conjugal (a família monoparental); a possibilidade de romper o casamento, especialmente para proteção contra violência doméstima, entre outras, que demonstram que o espaço da família é, atualmente, um espaço de promoção de realização pessoal, especialmente do público feminino.

Ter a oportunidade de divagar sobre aspectos históricos, sociais, culturais e jurídicos a partir de um enredo ficcional é, sem dúvidas, uma das maiores qualidades da Sétima Arte, papel esse que "Coisa mais linda" desempenha com louvor, levando não só o cinema, a música e a beleza natural brasileira ao conhecimento mundial, como também divulgando ao mundo toda a fibra da mulher brasileira.

\section{REFERÊNCIAS}

ALVES, Clarissa Cecília Ferreira. Ponderações feministas acerca do Direito: a proteção do casamento no Direito de Família brasileiro enquanto manutenção do modelo patriarcal de família. Disponível em: <http://www.publicadireito.com.br/artigos/?cod=171ae1bbb81475eb>. Acesso em: 03 abr. 2019.

AZEVEDO, Álvaro Villaça. Direito de família. São Paulo: Atlas, 2013.

BARRETO, Ana Cristina Teixeira. Carta de 1988 é um marco contra discriminação. Consultor Jurídico - CONJUR. 5 de novembro de 2010. Disponível em: < 
https://www.conjur.com.br/2010-nov-05/constituicao-1988-marco-discriminacaofamilia-contemporanea >. Acesso em: 03 abr. 2019.

BARROS, Sergio Resende de. Direitos humanos da família: dos fundamentais aos operacionais. In Afeto, Ética, Família e o novo Código Civil. Coordenador: Rodrigo da Cunha Pereira. Belo Horizonte: Del Rey, 2004.

BERTOLIN, Rosangela Violetti. BRITO, Mozar José de. Análise Fílmica: Alternativa Metodológica na Pesquisa Organizacional Refletindo Subjetividade, Trabalho e Corporeidade. II Encontro de Gestão de Pessoas e Relações de Trabalho. 2011. Disponivel em: < http://www.anpad.org.br/admin/pdf/EnGPR398.pdf>. Acesso em: 03 abr. 2019.

BOURDIEU, Pierre. A dominação masculina. Tradução Maria Helena Kühner. Rio de Janeiro: Bertrand Brasil, 1999.

CIPOAL. Dicionário online Michaelis. 03 abr. 2019. Disponível em: < http://michaelis.uol.com.br/busca?id=0AGP >. Acesso em: 03 abr. 2019.

DIAS, Maria Berenice. A mulher e o direito. Disponível em: <http://www.mariaberenice.com.br/manager/arq/(cod2_732)23_a_mulher_e_o_direi to.pdf>. Acesso em: 03 abr. 2019.(a)

DIAS, Maria Berenice. A mulher no Código Civil. Disponível em: < http://www.mariaberenice.com.br/uploads/18_-_a_mulher_no_c\%F3digo_civil.pdf>. Acesso em: 03 abr. 2019.(b)

DIAS ALMEIDA, Natália Kelle; COELHO, Maria Thereza Avila Dantas. A violência estrutural. SEPA. Seminário Estudantil de Produção Acadêmica, v. 11, p. 1-11, 2007. Disponível em: <https://revistas.unifacs.br/index.php/sepa/article/viewFile/323/270>. Acesso em: 03 abr. 2019.

EM 15 ANOS, o número de famílias chefiadas por mulheres mais que dobra. Agência O Globo. 06 de março de 2018. Disponível em: < https://epocanegocios.globo.com/Economia/noticia/2018/03/em-15-anos-numero-defamilias-chefiadas-por-mulheres-mais-que-dobra.html>. Acesso em: 03 abr. 2019.

FARIAS, Cristiano Chaves de; ROSENVALD, Nelson. Direito das famílias. 2. ed. Rio de Janeiro: Lumen Juris, 2010.

FERRERO, Clara. O vocabulário feminista que todos já deveriam estar dominando em 2017. El País. 12 de julho de 2017. Disponível em: $<$ https://brasil.elpais.com/brasil/2017/07/10/cultura/1499708850_128936.html>. Acesso em: 04 abr. 2019.

GOMES, Laurentino. A família na história do Brasil. Revista IBDFAM, Belo Horizonte, n. 5, p. 6, nov. 2013. Entrevista. 
MADALENO, Rolf. Curso de direito de família. 4. ed. rev. ampl. e atual. Rio de Janeiro: Forense, 2011

MAGALHÃES, Lívia. De incapaz a livre: a evolução dos direitos da mulher na família. Portal Azmina. 12 de abril de 2016. Disponível em: < https://azmina.com.br/colunas/entenda-quais-sao-os-direitos-da-mulher-dentro-dafamilia/ >. Acesso em: 03 abr. 2019.

PEDROSO, João. BRANCO, Patrícia. Mudam-se os tempos, muda-se a família. As mutações do acesso ao direito e à justiça de família e das crianças em Portugal. Revista Crítica de Ciências Sociais, 82, Setembro 2008: 53-83. Disponível em: $<$ https://journals.openedition.org/rccs/619>. Acesso em: 03 abr. 2019.

PITANGUY, Jacqueline. BARSTED, Leila Linhares. Um instrumento de conhecimento e atuação política. In: O Progresso das Mulheres no Brasil 2003-2010 / Organização: Leila Linhares Barsted, Jacqueline Pitanguy - Rio de Janeiro: CEPia ; Brasília: ONU Mulheres, 2011. Disponível em: < http://onumulheres.org.br/wpcontent/themes/vibecom_onu/pdfs/progresso.pdf>. Acesso em: 03 abr. 2019.

PITANGUY, Jacqueline. Advocacy: um processo histórico. In: O Progresso das Mulheres no Brasil 2003-2010 / Organização: Leila Linhares Barsted, Jacqueline Pitanguy - Rio de Janeiro: CEPia ; Brasília: ONU Mulheres, 2011. Disponível em: < http://onumulheres.org.br/wp-content/themes/vibecom_onu/pdfs/progresso.pdf>.

Acesso em: 03 abr. 2019.

PORTO, Walter Costa. Dicionário do voto. Brasília: UnB, 2000. Disponível em: < http://www.tse.jus.br/eleitor/glossario/termos/voto-da-mulher>. Acesso em: 03 abril. 2019.

RODRIGUES, Silvio. Breve Histórico sobre o direito de família nos últimos 100 anos. Revista da faculdade de direito, USP, v. 88, São Paulo, 1993. Disponível em: < http://www.revistas.usp.br/rfdusp/article/viewFile/67221/69831>. Acesso em: 03 abr. 2019.

RUZYK, Carlos Eduardo Pianovski. Famílias simultâneas: da unidade codificada à pluralidade constitucional. Rio de Janeiro: Renovar, 2005

SANTOS, Tania Maria dos. A mulher nas constituições brasileiras. In: II Seminário Nacional de Ciência Política: América Latina em debate. Porto Alegre: Ufrgs. 2009. Disponível em: <http://www.ufrgs.br/nucleomulher/arquivos/Mulher\%20e\%20CF\%20\%20Final\%20tania.pdf>. Acesso em: 03 abr. 2019.

SCHNEIDER, Giselda Siqueira da Silva. Mulher, Direitos e Cidadania: uma reflexão a partir da História da Mulher no Brasil e da Constituição Federal de 1988. In: ESTEVES, Juliana Teixeira; BARBOSA, José Luciano Albino; FALCÃO, Pablo Ricardo de Lima. (Org.). Direito, Gênero e Movimentos Sociais II. 1ed.Florianópolis: CONPEDI, 2014,
v.
2,
p. 303-317.
Disponível
em:
$<$ 
http://publicadireito.com.br/artigos/?cod=3ad69dbde4c12dfc>. Acesso em: 03 abr. 2019.

SOUZA, Ivone M. C. Coelho de. DIAS, Maria Berenice. Evolução feminina, como se insere na família? Disponível em: $<\mathrm{http}: / /$ www.mariaberenice.com.br/manager/arq/(cod2_728)10_evolucao_feminina_ como_se_insere_na_familia.pdf>. Acesso em: 03 abr. 2019.

WAQUIM, Bruna Barbieri. SOUSA, Monica Teresa Costa. Do direito de família ao direito das famílias: a repersonalização das relações familiares no Brasil. Revista de Informação Legislativa, Ano 52 Número 205 jan./mar. 2015. Disponível em: < https://www12.senado.leg.br/ril/edicoes/52/205/ril_v52_n205_p71.pdf>. Acesso em: 03 abr. 2019. 